\title{
Adult cardiopulmonary bypass in the twenty-first century. Science, art or empiricism?
}

\section{Circulação extracorpórea em adultos no século XXI. Ciência, arte ou empirismo?}

\author{
André Lupp MOTA ${ }^{1}$, Alfredo José RODRIGUES², Paulo Roberto Barbosa ÉVORA ${ }^{3}$
}

RBCCV 44205-953

\section{Abstract}

The present review has for objective to stand out some aspects little argued of the cardiopulmonary bypass (CPB), taking in consideration physiology, physiopathology and some new technologies of perfusion. Thus, some points, sometimes philosophical, had motivated the elaboration of this revision: a) To preserve and to bring up to date the surgeon CPB knowledge, for the simple fact to even keep its pedagogical leadership on its team; b) To question if patient aged and/or diabetic, for its individual characteristics, deserved more appropriate protocols as well as adopted for children; c) One third aspect would be the questioning of the systemic inflammatory reaction caused by the exposition of the blood to CPB non-endothelized circuit surface ahead of the increasing importance of the wound surgical contact of the blood; d) In relation to the treatment of the vasoplegic syndrome, methylene blue continues being the best therapeutical option, even so, many times are not efficient because of a highly probable existence of a "therapeutical window" based in the guanylate cyclase dynamics of action (saturation and synthesis "de novo") and; finally, e) The reason of the choice of the heading standing out that, in its current patterns, the CPB would be consequence of empirism, art, or science. The final message comes with the certainty of that as much the empirism, art and science are very strong concerning $\mathrm{CPB}$.

Descriptors: Extracorporeal circulation. Cardiopulmonary bypass. Cardiac surgical procedures.

1. Monitor of the Discipline of Thoracic and Cardiovascular Surgery of the Anatomy and Surgery Department - FMRP - USP; Graduate student in Medicine - FMRP-USP

2. PhD Professor of the Anatomy and Surgery Department - FMRPUSP; Vice-coordinator of the Postgraduate program of the Anatomy and Surgery Department - FMRP-USP.

3. Titular Professor; Head of the Anatomy and Surgery Department - FMRP-USP

This study was carried out at the Anatomy and Surgery Department of the Ribeirão Preto Medical School of the University of São Paulo, São Paulo, SP, Brazil.

Correspondence adress: Paulo Roberto B. Évora. Rua Rui Barbosa, 367, Apt. 15. - Ribeirão Preto - SP - Brasil - CEP: 14015120

E-mail:prbevora@netsite.com.br

Support: State of São Paulo Research Foundation (FAPESP), and Foundation for the Support of Teaching, Research and Assistance (FAEPA) - of the Hospital das Clínicas of the Ribeirão Preto Medical School of the University of São Paulo. 


\section{Resumo}

A presente revisão tem por objetivo ressaltar alguns aspectos pouco discutidos da circulação extracorpórea (CEC), levando-se em consideração fisiologia, fisiopatologia e algumas novas tecnologias de perfusão. Assim, alguns aspectos, até certo ponto filosóficos, motivaram a elaboração dessa revisão: a) Preservar e atualizar os conhecimentos do cirurgião sobre a CEC, pelo simples fato de manter a sua liderança pedagógica sobre a sua equipe; b) Questionar se pacientes idosos e diabéticos pelas suas características individuais, assim como adotado para crianças, talvez merecessem protocolos mais apropriados; c) Questionar a reação inflamatória sistêmica causada pela exposição do sangue à superfície não endotelizada do circuito de CEC

\section{INTRODUCTION}

Among all surgery modalities known today, the heart surgery was one of the few that only in the last century has become bravely discovered by surgeons, and the ways gone through since then - initially frightening maze), are today safe ways due to the tenacity and commitment of several scientists. The cardiopulmonary bypass (CPB) was the responsible for the achievement of this status because due to this procedure, the heart surgeries have become safer and some more complex defects could be approached.

This review aims to highlight some little discussed aspects of the CPB, taking into account aspects of physiology and physiopathology aspects and some new perfusion technologies. Thus, some aspects (partly philosophical aspects) motivated the development of this review.

The first of these aspects concerns to the fact that the surgeons no longer worried about the CPB, since the perfusionists began to make a quality support, besides the technical performance of the procedure. In our opinion, the surgeons must maintain and update their knowledge about CPB due to the simple fact of maintaining its educational leadership over their team. On the other hand, it seems that diante da importância crescente do contato do sangue com a ferida cirúrgica; d) Em relação ao tratamento da síndrome vasoplégica, o azul de metileno continua sendo a melhor opção terapêutica, embora, muitas vezes não seja eficiente pela existência de uma “janela terapêutica” embasada na dinâmica da ação da guanilato ciclase (saturação e síntese “de novo”) e; finalmente, e) Razão da escolha do título, ressaltando que, em seus moldes atuais, a CEC seria conseqüência do empirismo, arte, ou da ciência? A mensagem final vem com a convicção de que tanto o empirismo, a arte e a ciência são muito fortes em se tratando da CEC.

Descritores: Circulação extracorpórea. Ponte cardiopulmonar. Procedimentos cirúrgicos cardíacos. there are certain complacency in relation to the $\mathrm{CPB}$, since in recent times the quality of the CPB apparatus ensures a great safety for heart operations.

The second aspect concerns an interesting detail. The $\mathrm{CPB}$ techniques are clearly divided into protocols for children and protocols for adults. But among adults would not be interesting the preparation of protocols individually? For example, the elderly and diabetics, due to their individual characteristics: Wouldn't they deserve more appropriate protocols?

The third motivational aspect of this review may be the questioning of so harmful systemic inflammatory reaction caused by exposure of blood to the nonendothelized surface of the CPB circuits. Due the fact that the inflammatory response is present in patients undergone off-pump surgery, the focus has changed to the concept that, more than the contact with the CPB circuit, the contact of the blood with the operatory wound may be the most responsible by the inflammation phenomenon in CPB. This even induced to the consideration of the contact of the blood with serous (pleura and pericardium), which have, as is well known, fibrinolytic activity as cause of increased bleeding. Thus, the maintenance of the pleural integrity in the dissection 
of the internal thoracic arteries has become an interesting detail of surgical technique.

Finally, what is the reason for the title of this review? Regarding the CPB in its current patterns, would it be consequence of empiricism or science? We are convinced that both empiricism and science are very strong. Thus, the greatest motivation of this review was to provide knowledge in order that the teams involved in cardiac surgeries may standardize their knowledge about CPB and pursuit the enhancement of the scientific aspects that guide the procedure.

\section{MICROCIRCULATION}

The cardiovascular system is a complex set of vessels, within which the blood circulates through the body, pumped by the heart. In this way, the veins are responsible for the flow in centripetal way, whereas the arteries are responsible for the flow in centrifugal way. Interposed between the more distal arterial and venous territories are the constituents of the microcirculation, composed of arterioles, capillaries and venules. It deals with the place where the exchanges between the blood and tissues take place and where are the regulatory mechanisms of peripheral blood flow. The flow regulation in the capillary bed occurs by means of the arteriovenous communications - which can defflect the blood from the capillaries - and by means of the pre- and post-capillaries sphincters, which actions control the blood volume and the pressure in the capillary bed. The flow control in the microcirculation complies to metabolic changes as for both hormonal or neural stimuli [1]. We can emphasize that during the CPB the physiology of circulation is completely modified by the introduction of a nonpulsatile flow of the arterial side that differs from a high venous pressure on the venous side of the circulation (Figure 1). This situation induces to adaptation mechanisms and those main are represented in Figure 2.

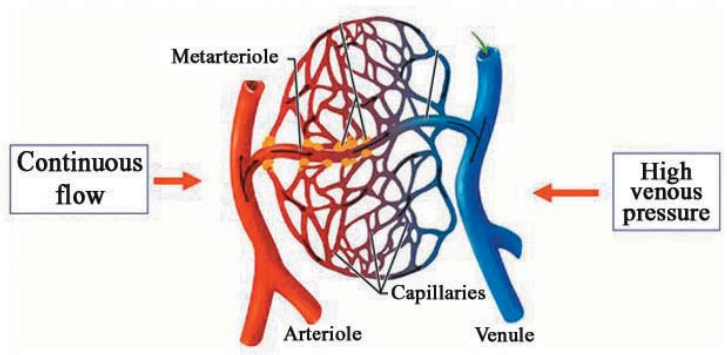

Fig. 1 - Microcirculation in cardiopulmonary bypass (CPB)

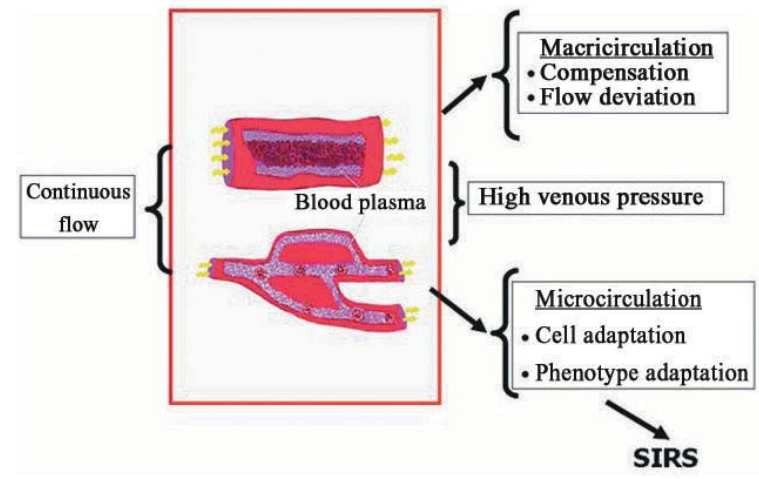

Fig. 2 - Microcirculation in cardiopulmonary bypass (CPB)

\section{Adaptation mechanisms}

Throughout all their extension, the components of the cardiovascular system are coated by three basic tissue layers, suffering variations on the thickness in the different types of vessels that constitute the system. These layers are: a) intima layer, more internal, consisting of endothelium, which primary function is to avoid the contact of blood with endhotelial thrombogenic substances b) thickness of the media layer, consisting (in more or less intensity) of elastic and muscle tissue and; c) Adventitia or external layer, primarily composed of conjunctive tissue [1.2].

In the pressure gradient found along the circulation, the pressure has a greater value in the left ventricle reaching (during the systole), the mean value of $120 \mathrm{mmHg}$, decreasing then in the diastole and reaching around $0 \mathrm{mmHg}$. At the aortic root, the systolic pressure has the same value found in the heart, however, the diastolic pressure decreases to around $80 \mathrm{mmHg}$. It may be explained by the storage of energy imposed by the blood on the arterial wall during the systole and released during the diastole, ensuring the flow throughout all cardiac cycle. In the more distal arteries, both values of systolic or diastolic pressure decrease in relation to the origin of aorta, as well as the pressure and pulse (that is the difference between the systolic and diastolic pressure).

The pulse pressure reaches zero value from the capillary territory and the difference between the pressure of the arteriolar extremity (about $40 \mathrm{mmHg}$ ) and the venous extremity (about $20 \mathrm{mmHg}$ ) creates a decreasing pressure gradient along the capillary. In the return to the heart along the venous system, the blood pressure gradually decreases until reaching value around zero in the right atrium [2].

The microcirculation morphology is not uniform in all organs of the body, thus, in the central nervous system, in the lungs, skin and in the skeletal muscle, the 
capillary endothelium is of continuous type. The intestinal mucous, the exocrine glands, the renal glomerulus and the Choroid plexus are composed of fenestrated-type endothelium. Finally in the liver, spleen and bone marrow, the endothelium is of discontinuous type [2]. Regarding to the microcirculation flow, it is not pulsatile as in the arteries, because the pulse pressure in the territory is null. Moreover, the flow in capillaries is intermittent because the contraction in the pre-capillaries sphincters may block the passage of blood during rest, allowing that the capillaries may oscillate opened and closed.

The use of cardiopulmonary bypass (that in the majority of cases occurs with no pulsatile flow) is considered harmful to the microcirculation, thus providing a "shunting" effect. Moreover, the technique is responsible for other changes in circulation, such as replacement of reflex and chemoreceptors controls; increase of venous pressure; decreasing of colloid osmotic pressure and manipulated temperature. The replacement of the physiological controls induces the capillary flow to not be intermittent and to be continuous instead, which increases the pressure on the venous side forcing - in the microcirculation - the performance of compensation mechanisms for flow deviation. In the microcirculation, the continuous flow induces to phenotypic cell adaptation that results in the development of systemic inflammatory response syndrome (SIRS)[2]. Once initiated this response occurs activation of inflammatory cells and initiation of coagulation cascade It also occurs the release of cell signaling protein, generation of vasoactive and cytotoxic substances in addition to production of a diversity of microembulus.

Another way of microcirculation lesion related to the use of CPB is the formation of microbubbles that circulate in the blood flow and lodge in the capillaries causing obstruction, promoting ischemia, inflammation, complement activation, platelet aggregation and formation of blood clots [3].

In last decades, occurred considerable advances in CPB equipments in order to avoid the development of SIRS. This achievement has had some success, but we can not affirm the same regarding to microcirculation lesion. The damage caused in the microcirculation can be evidenced by the detection of products of several organs degradation and is undoubtedly an important function to help the perfusionists to improve their techniques. One of the markers that may meet this function may be the "mitogen-activated protein kinases" (MAPK), that have been involved in the vasomotor function, since the microcirculation regulation includes the miogenic tone [4].

\section{CPBMONITORING}

Up to now, there is no method for monitoring of the regional infusion during the $\triangle P B$, which leads to the question about which markers could be used to determine adequacy of arterial flow during the CPB. A discussion about possible parameters that may meet this purpose are here presented as follows. This discussion was presented by one of the authors (PRBE) in 2007 in the $34^{\text {th }}$ Congress of the Brazilian Society of Cardiovascular Surgery [2].

\section{Oxygen partial pressure of venous blood (PvO2) and venous saturation of venous blood (SvO2)}

The SvO2 presents some problems, among them, the fact that if the distant capillaries are not equally perfused, tissues may not receive appropriate flows resulting in increase of the $\mathrm{PVO} 2$ or SVO2, mimicking a vascular shunt. Thus, the PVO2 or SVO2, despite the fact that they are markers easy to be measured, they may not be related to the appropriate infusion tissue, not necessarily suggesting that the cell oxygenation is satisfactory [5].

\section{Lactate}

Among the problems presented by the lactate, we may mention that the release of this substance in the blood demands blood flow; thus, high levels may be typically identified later in the postoperative [5]. For the measurement of intraoperative lactate, the lactate/pyruvate relationship may be a better method, but requires additional analytical instrumentation. The systemic microvascular control may be disordered in the nonpulsatile $C P B$, resulting in "shunting" with increased levels of lactate, despite an apparent appropriate supply of oxygen. Extreme hemodilution, hypothermia, low flow of CPB and excessive neuronal activation have been related to lactic acidosis during $\mathrm{CPB}$.

\section{Partial pressure gradients of carbon dioxide between the venous and arterial blood samples (" $\mathrm{PCO}_{2}$ )}

The PCO2 gradient between the arterial and venous blood samples ( $\triangle$ PCO2) is a valuable parameter for determining the adequacy of the $\mathrm{CPB}$ for a certain metabolic condition and may help to detect alterations in oxygen demand (metabolic alterations that accompany the temperature changes, CPB flows and drugs administration). Amongst the SvO2, which is valuable patient's metabolic index during $\mathrm{CPB}$, the $\triangle \mathrm{PCO} 2$ can help to fulfil the role in the adequacy of the tissue perfusion during surgery. This gradient, perhaps one of the best parameters of tissue perfusion is rarely used by our perfusionists perhaps due to its lack of knowledge. 


\section{Arterial pressure}

Arterial pressures are very important in determining the adequacy of $\mathrm{CPB}$, but is difficult to establish what pressure level may indicate a best perfusion for each patient and their physiopathological particularities.

\section{TECHNOLOGIES}

The introduction of CPB apparatus has solved obstacles that did not allow the access to the inner cavity of the heart; however, this fact revealed a myriad of complications from the response of the organism to the aggressions imposed by the apparatus. Thus, throughout the years after the introduction of the $\mathrm{CPB}$, a paradoxical and new situation of a number of complications related to the use of CPB were observed. Among these problems, the main are related as follows: a) the severe inflammatory response that the patients develop when their blood are exposed to nonendothelial surface of the apparatus, b) the excessive hemodilution or the need of use of homologous blood to fill the circuit, and c) the microcirculation lesion caused by the type of flow imposed by the apparatus pumps.

Some technologies have been developed, modernly, aiming at the resolution of these problems. Herein, we will approach some of these major advances.

\section{Retrograde autologous priming}

Since the creation of CPB, the cardiac surgeries present high risk for blood transfusion. That's because, in addition to the bleeding inherent to the surgery, often the procedure results in severe hemodilution, since the CPB circuit should be filled with some substance to remove the air in the system

Initially, homologous blood was used for this purpose, but the risk of disease transmission and the lack of donors contributed to the search for alternative materials. The introduction of crystalloid substances to fill the circuit (the called "pattern technique") solved that question, but the frequent severe hemodilution induces to the need of new transfusions. Moreover, the hemodilution presents undesirable effects such as decreasing of the blood osmotic pressure and its inability to carry oxygen causing acidosis, hypoxia, edema and clotting alterations [6]. Studies evaluating the hemodilution effects showed association with high rates of mortality and other adverse conditions, which occur mostly when the hematocrit levels are lesser than $20 \%$. The low hematocrits during the CPB are associated to an increase of hospital mortality risks with need of use of an intra-aortic balloon in per- or postoperative and the need to return to the perfusion after the end of CPB. In addition to these results, ethical and religious pressures against blood transfusions, the scarcity of material and the risk of disease transmission induce to the search for other means to fill the system.
The resolution for these problems was attempted by the introduction of a new technique, the Retrograde Autologous Priming (RAP), described initially by Panico and Neptune [7] in 1959, and adapted later by several authors $[5,8,9]$. The basic idea consists of filling the CPB circuit with the patient's own blood. To this end, the circuit is initially filled with crystalloid solution and then, allowing that the blood retrogradly flows from the aorta of the patient to the arterial line, moving part of the acellular prime that was in the arterial line to the bag collector. After that, the forceps of the venous line is opened allowing the venous blood drainage of the patient. At the same time, the arterial pump is slowly moved in order to maintain a constant liquid level in the venous reservoir. Then, the blood moves the remaining solution of the circuit to the bag and the CPB may be initiated. If there is need of liquid addition during the perfusion, the prime stored in the collector bags can be introduced in the circuit by means of the recirculation line. The technique of RAP has proved to be a safe, low cost and very effective in reducing the hemodilution associated to the heart surgery. This provides a blood viscosity closer to the physiological blood, does not change the values of plasmatic proteins, contributing to a better balance in osmotic pressure and reduction of edema. Moreover, the technique does not compromise the function of the clotting factors and the vessel-regulator hormones. As previously mentioned, the technique reduces the need of blood transfusions and allows the control of the hematocrit to reache the intended levels by manipulating the amount of crystalloid released by the backup bags. The use of the technique is also associated with lower hemodynamic instability by allowing a rapid perfusion initiation. The potential risks of the use of RAP technique are related to the reduction of hemodilution because the patients who are under hypothermia may present increase in the blood viscosity about $10 \%$ to $30 \%$. This can be solved by a moderate hemodilution during the procedure, avoinding microcirculation impairment.

\section{Pulsatile flow}

The blood arterial flow in the organism is a pulsatile type, or that is, with changes in pressure during systolic and diastolic phases; however, since its invention, the CPB determines a nonpulsatile flow, or that is, the pressure does not undergo significant variations over the perfusion. That difference regarding the physiological flow raised the suspicion that a mechanism that may provide a pulsatile blood flow may provide a most appropriate and less harmful perfusion inducing a serie of comparative studies between the two systems. Promising results, showing hemodynamic and metabolic improvement -compared to the 
conventional method - point to the pulsatile flow as an important tool to reduce complications associated with the use of CPB [10-12].

It was suggested that the most benefic effect of the use of pulsatile flow may be in the territory of the microcirculation, where the energy of the pulsatile flow eases the interstitial diffusion by the oscillation of cell membranes and promotes the arterioles patency (which remain collapsed during the nonpulsatile flow). In addition to this is the fact that the continued opening of arterioles reduces the stress produced by the decreased release of endothelial vasodilators.

Although the literature presents conflicting data, many researchers have shown that the pulsatile flow improves cerebral blood flow as well as avoiding the drop of renal function and tubular changes found during the use of nonpulsatile flow. Moreover, it was demonstrated that the use of the technique increases the urine output and reduces proteinuria. It seems logical that the pulsatile flow is important or even needful to maintain the body's physiological state, then, in order to the extracorporeal support system may mimic the characteristics of pressure and flow as close as possible of the physiological characteristics, it is need to seek the exact wave type needed to reach a good pulsatile flow by the artificial pumps. This is a controversial aspect, since there are defenders that only the presence of any pulse already shows benefic effects.

\section{Minicircuits}

The severe inflammatory response associated with the materials used in СРВ apparatus has raised the idea that the reduction of the size of circuits may reduce the degree of this response and minimize the harmful effects of the $\mathrm{CPB}$; moreover, minor apparatus may reduce the prime quantity needed and may minimize the hemodilution and the need for homologous transfusions.

The concept of mini-CPB combines the known clinical advantages of the impregnated circuits, reduction of the prime volume and reuse of the aspirated blood from the surgical field. These circuits are composed of a centrifugal pump, a membrane oxygenator, a heat exchanger, a "cell saver" system for blood collection from the surgical field and an alterial filter, due to the higher risk of air entering that these systems have [13].

Initially created to be used in CABG; throughout the time and with increasing experience of the teams, the miniCEC has been showing increasingly useful, expanding the number of indications for more complex procedures and replacing the conventional systems. A comparative study between patients undergone conventional system and miniCPB revealed some number of microbubbles in the conventional system increasing the chances of these patients to develop cognitive deficits [14]. Another study of the same nature revealed that the use of mini-CPB's reduces hemodilution and thus the need for homologous transfusions associated to the procedure. These observations in the study were associated with postoperative bleeding reductions.

Despite the small number, the studies related to the new system have been showing superiority in the benefits of minicircuits in relation to conventional systems up to now. Future studies should be made to expand the indications on its use in larger number of procedures.

\section{Impregnated circuits}

The interaction between the blood and non-endothelial surfaces of the CPB circuit is responsible for the development of severe inflammatory response based on the activation of complement and the kallikrein system. In addition to that, the release of cytokines contributes to severe complications in the peri- and postoperative and increases the surgical morbidity and mortality. These problems can be solved by means of materials that allow the biocompatibility to the system, or that is, materials that avoid the deleterious effects of non-endothelial materials of the apparatus in contact with the patient's blood. It was proven that the heparin - commonly used due to its antithrombotic properties - is capable of providing properties of biocompatibility, inhibiting by the contact the activation of complement and adsorving lipoproteins to create a surface that mimics the cell membranes.

The use of heparin in the coating of the $\mathrm{CPB}$ apparatus has proved to be capable to reduce blood loss, as well as the need for blood transfusions or derivatives. Moreover, the achieved reduction of inflammatory response has benefic effects on the patient's clinical evolution. Mangoush et al. [15] also showed that the substance reduced the ventilation time in 78 minutes, as well as the hospitalization time in 0.5 days. Because of these reductions, the use of the mentioned substance also allows important economy in terms of financial costs.

Another type of coating that allows biocompatibility to the system is the Phosphorylcholine, a phospholipid that has been incorporated to a copolymer (methacryloylphosphorylcholine/lauryl-methacrylate (MPC:LM). Its characteristics allow coating of other polymers, showing stability and little waste by leaching. It has proved that the coating resists to the fibrinogen adsorption, connection and activation of platelets [16.17]. The effects on the clinical status of the patient still need further studies, but in the few performed studies was found the reduction of immediate postoperative bleeding, preservation of platelets and a positive effect on the generation of complement.

A third group of products is also commercially available and involves the concept of "microdomains" to minimize the interactions between the surface, the cells and the 
proteins. It is known that the proteins adsorption (including fibrinogen) is more significant on hydrophobic surfaces, while the hydrophilic surfaces promote activation of complement. The new technology uses copolymers, from which hydrophobic and hydrophilic “microdomains" are interchanged on the surface of contact with blood. The control of the distances among these "microdomains" allows them to compete among themselves ("microdomain" inhibiting the effect of another), which limits the adsorption of protein [18].

The cell membranes of circulating leukocytes and platelets are also under the same competitive interaction between the surface and the membrane constituents minimizing the cellular connection. A few clinical studies have shown inhibition of the generation of thrombin and fibrinolysis during the use of these coatings. Moreover, there is protection of platelets with reduction of their activation.

Some other materials are commercially available but almost all of them still requiring more studies to confirm their benefits. Future advances in materials engineering focusing the search of products with high biocompatibility will allow better results in reducing complications by the use of CPB.

\section{CARDIOPULMONARY BYPASS INELDERLY}

In recent years, world population is going through an "aging process". This increase of the elderly population additionally brings increase of the prevalence of diseases inherent to this age-group, among them the cardiovascular diseases. As a result, the heart surgery in elderly has been frequently increased and some procedures, such as CABG, correction of valve lesions (specially the aortic valve), and repair of aneurysms and dissections of the aorta are becoming common.

The peculiarities of this population bring as a challenge to patients selection the adoption of peri- and postoperative cares, and the choice of surgical techniques that reduces the morbidity and mortality in those patients. In order that an elderly patient may undergone to a high-risk surgical procedure is necessary to understand the physiological alterations in order to observe the physiological status and anticipate no physiological alterations as early as possible. It is also important to analize the benefits in the expectation and quality of life that a specific intervention will bring to the patient [18.19].

Some physiological aspects of aging involve in well known particularities such as cardiovascular, lung and kidney physiologies, which are extremely important for the CPB planning. These particularities of the elderly physiology justify one of the initial propositions of this study (special protocols for elderly), motivating also the pursuit for excellence in pre- and perioperative care of these patients. Preexisting diseases have greater impact on morbidity and mortality than this age for itself. Meanwhile, although the age alone does not constitute a risk factor for heart surgery, it may not be an extreme the individualization of CPB protocols for elderlies [18.19].

The preparation of the CPB does not differ significantly from the perfusion for adults in general, however, taking into account that the elderly is characterized by reduced organic reserves, it needs higher stability during perfusion. The peculiarities of the elderly include higher systolic pressure due to greater rigidity of the arteries, reduction of the blood flow brain and lower oxygen consumption by the tissues. Also, due to higher incidence of neurological complications by microembolia, it is recommended the use of the filter in the arterial line. Other recommendations include to maintain blood pressure at higher levels than the average $70-80 \mathrm{mmHg}$ at all stages of the infusion; the hematocrit between 25 and 30\% and an oncotic normal pressure, which is obtained by adding synthetic colloids, plasma or albumin, avoiding cerebral and pulmonary edemas. Concerning to the temperature, it is preferable the normothermia or rapid hypothermia [20].

\section{PATIENT}

It is known that diabetic patients - when undergoing on-pump heart surgery - present rate of severe complications and its oxidative stress is about two times higher compared to non-diabetics patients. Furthermore, some studies have reported that the inflammatory response is different when the two groups are compared. Despite not yet entirely known, the metabolism of nitric oxide (NO) was involved as participating of these alterations. The different possible mechanisms already outline therapeutic possibilities to reduce the deleterious effects of the CPB in these patients.

The suspicion that the NO may be involved in the physiopathology related to the use of CPB motivated many studies, many of them comparing different parameters between diabetics and non-diabetic patients. Matata and Galiñanes performed a study in which they measured the stable metabolites levels of NO (NOx) in urine and blood. These metabolites are the main way of NO degradation and due the fact that they do not suffer immediate degradation, their measurement is a reliable indication of the production of NO. The results showed that NOx levels are already high in basal conditions in the diabetic group, explaining the greater susceptibility to oxidative stress. Moreover, the levels of these metabolites suffer significant additional increase during heart surgery that was not observed in the non-diabetic group [21.22]. 
It is known that the reaction between $\mathrm{NO}$ and the superoxide anions induces to the formation of powerful oxidizing peroxynitrite (ONOO-), which can exacerbate the oxidative stress in diabetics. Those peroxynitrites are the major generators of hydroxyl radicals that are known by causing serious lesion and cell death. Moreover, the free radicals generated during the CPB induce to peroxidation of lipids and proteins that change the enzyme activity. Due the fact that the pre-treatment with antioxidants before the CPB reduces oxidative attack, interventions with antioxidants may represent possible therapeutic aim.

It is suspected that the cause of increase of NO is the increased expression of inducible NO synthase (iNOS) in these patients [21]. The suspition of implication of the NO in the physiopathology of the adverse events observed after CPB has induced studies about NO donors. Moreover, these substances are usually used to hemodynamic control during and after $\mathrm{CPB}$, and the effects of exogenous $\mathrm{NO}$ on oxidation and inflammatory response concerning the clinical status of patients was unknown.

These studies showed that exogenous NO significantly reduced the oxidative stress in diabetic patients and differently affected inflammatory response between the groups of diabetics and non-diabetics [22]. In these two groups of patients, the use of NO donors decreased the formation of nitrotyrosine protein, but only in diabetics there was significant reduction in formation of lipid hydroperoxides and protein carbonylation. These observations may be explained by the reduction of formation of endogenous NO by means of exogenous NO. Thus, the results showed that exogenous NO seems to present a powerful antioxidant activity in humans, which may allow the extension of its use in addition to the usual hemodynamic control.

Alteration in NOx levels also were compared in response to the administration of nitroglycerin (TNG), revealing that this substance, in accordance with the findings described above, is also able to significantly reduce urinary and plasmatic levels of NOx in diabetics. One hypothesis about the way the TNG exerts this effect on NO metabolism may be by the negative regulation on the activity of constitutive NOS. Another possibility may be that the TNG reduces the capture of L-arginine (precursor of NO) by cells, emphasizing that the two mechanisms are not mutually exclusive and may occur together, inducing the reduction of the Nox levels in diabetics [22].

Study about the use of TNG on the inflammatory response [21] showed that this drug increased the IL-8 levels and plasma elastase in diabetics, whilst in nondiabetic group there was increased of complements activation. These findings show that the inflammatory response in diabetic patients is different from the response in non-diabetics and, moreover, the answer to the TNG is also different between the two groups.

There are also reports of minor hospital stay (marginally not significant) in diabetic patients who received TNG, although it increases the release of some components of the inflammatory response of CPB in both groups of patients. Thus, despite the benefits, the increase of the inflammatory response observed by NO donor drugs regarding to their use - requires care, especially in patients under proinflammatory conditions.

Other studies have shown reduction in the complement activation to the use of another NO donor (sodium nitroprusside) [23]. This may indicate that the donor type and the time of use, as well as the dose of administration may be important in determining the effect of these agents in the inflammatory cascade. Thus, as the oxidative stress is greater in diabetic patients, its reduction by NO donors may be a possible therapy.

\section{Vasoplegia in diabetics}

Another adverse effect of the use of CPB is the vasoplegic syndrome, which is characterized by the appearance, in the immediate postoperative period, of severe hypotension, reduction in systemic vascular resistance and in arteriolar reactivity and the increase of need for volume replacement and vasopressor therapy, and also cardiac output - although appropriate and even high. Nitric oxide mediators were discovered as participants of this syndrome, allowing also some therapies. Few studies characterize this syndrome in diabetics and, as previously discussed, diabetics present an altered NO metabolism; moreover, some differences in control of perfusion regulation between the two groups of patients are known [24].

The alterations presented in healthy patients along surgery induced to an increase in the pCO2 concentrations, acetylcholine, ADP, that with hypoxia stimulate the NOS to produce NO, which function is to regulate the flow by means of vasodilation. In diabetics, the changes that occur in this flow regulation mechanism are characterized by insufficient production of $\mathrm{NO}$, despite the presence of appropriate stimuli on the NOS. This effect sums to the thickening of the basal membrane and may block the passage of the little remainder NO that was produced, avoiding that it may reach the vascular smooth muscle and exerts its vasodilator effect [25].

\section{INFLAMMATORY REACTION AND VASOPLEGIC SYNDROM ASSOCIATED TO CARDIOPULMONARY} BYPASS

The physiopathology of post-CPB vasoplegia is multifactorial, with no final consensus on its real mechanism. The emphasis will be on systemic inflammatory 
reaction with possible "trigger" from the contact of blood with non-endothelial surfaces of CPB and the possible mechanism related to the vasopressin deficiency.

\section{Systemic inflammatory reaction}

The modern era of heart surgery had its beginning when the CPB technique was introduced in the beginnings of 50' decade. The CPB is essential for the majority of cardiac surgeries, but an undesirable inflammatory reaction occurs as a result of its use. Attempting to understand the physiopathology of the vasoplegic syndrome, a number of pathogenetic hypothesis has been suggested, including: a) viral and bacterial infections b) immunological reactions related to antimyocardial antibodies c) anaphylactoid reactions associated to anesthetics, protamine, heparin and the CPB circuit itself [26].

Many factors during the $\mathrm{CPB}$, dependent (exposure of blood to surfaces and not physiological conditions) or independent of the CPB material (surgical trauma, ischemia-reperfusion of the organs, changes in body temperature and release of endotoxins), have been well recorded as inducers of a complex inflammatory response. These factors include the activation of the complement system, release of cytokines, leukocyte activation and the expression of adhesion molecules, in addition to the production of various substances, such as oxygen free radicals, arachidonic acid metabolites, platelet-activating factor (PAF), NO and endothelins. Such inflammatory cascade may contribute to the development of postoperative complications, including respiratory failure, renal dysfunction, hemorrhagic disorders, neurological dysfunction, changes in liver function, and finally failure of multiple organs. More recently, it was observed that this antiinflammatory response may initiate during and after CPB. This complex chain of events has strong similarities with sepsis.

For the CPB circuit, it can be emphasized that its incidence is higher with the use of bubble oxygenators in relation to the membrane oxygenators. Its real physiophatology remains unclear and may be described a logical sequence of events: proinflammatory and/or inflammatory stimuli with activation of the complement system; release of various cytokines (interleukins, tumor necrosis factor, platelet activating factor, etc.); activation of the inducible nitric oxide synthase (iNOS); production of NO; activation of guanylate cyclase with an increase of cyclic GMP which leads to the refractory vasoplegia even to the use of high doses of adrenergic amines. There is also a tendency for diffuse bleeding by the NO antiplatelet activities of NO [26]. The schematic representation of this inflammatory response can be observed in Figure 3. Regarding the participation of $\mathrm{NO}$, it is curious to note that a clinical study with dose of nitrates in urine and blood of patients undergone on-pump heart surgery has not shown a correlation between endogenous NO and low systemic vascular resistance [27].

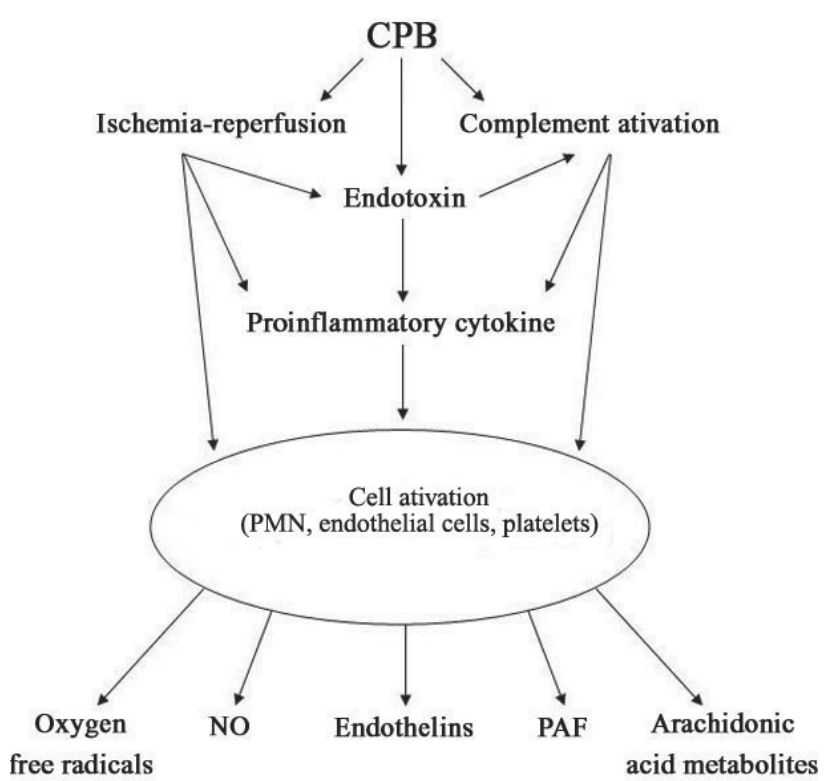

Fig. 3 - Outline of the inflammatory response generated by cardiopulmonary bypass (Acapted fromy Wan et al. 1997)

In relation to the individually involved mechanisms, some data worth highlighting:

1. The clinical relevance of the complement activation itself is still uncertain. Several studies have linked the postoperative morbidity to the complement activation;

2. The prevention of neutrophils adhesion may bring practical benefits, but these benefits may be associated to a greater risk of infection;

3. The leukocytes activation may release large amounts of oxygen free radicals, including the superoxide anion, 
hydrogen peroxide, hydroxyl radical and the oxygen itself. These radicals act on lipidic membranes by increasing the permeability which can involve the cardiac and pulmonary funcions;

4. The metabolism products of arachidonic acid (prostaglandins, leukotrienes and thromboxane A2) may be counterbalanced by the concomitant production of vasodilators prostaglandins such as the prostacyclin (PGI2). The leukotrienes may be responsible for the increase of capillary permeability;

5. Endotoxin levels may increase during and after $\mathrm{CPB}$. The sources of endotoxins are highly diverse, however, the most important source is related to the intestines. The splanchnic vasoconstriction during the CPB may induce to ischemia and increase of the permeability of intestinal loops with release of endotoxins into the blood flow. The endotoxins levels are related to the initial vasoconstriction, time of aortic clamping and hypo-oncotic state during the CPB;

6. The release of cytokines may be stimulated by a number of factors, including ischemia-reperfusion, the complement activation, the release of endotoxins and the effect of other cytokines;

7. The platelet-activating factor (PAF) has important role in the lesion of myocardial ischemia-reperfusion and may also have hemodynamic deleterious effects during the CPB;

8. The excessive production of NO, by the expression of iNOS, may be the result of these multiple mechanisms, being the biggest cause of the vasoplegic syndrome;

9. There may be increase of endothelin levels during the $\mathrm{CPB}$, surgical treatment of congenital cardiopathies, valve disease and CABG. Its role is not very clear in the physiopathology of the post-CPB vasoplegia. Anyway, if the vasoplegia is a consequence of a large release of NO, its opponent vasoconstrictor effect does not manifest.

\section{Vasopressin-dependent mechanisms}

Landry et al. [28] showed that the levels of vasopressin in septic shock are abnormally low. This fact supports the hypothesis that in sepsis there may be a decrease in vasopressin stocks and/or a baroreflex dysfunction, causing an insufficient secretion of vasopressin. These authors reported also situations of sepsis with refractory hypotension, which was recovered by the injection of vasopressin that led to a reduction of the needs of catecholamines.
Considering the similarities of the inflammatory response in sepsis and in post-CPB vasoplegia, Argenziano et al [29] published a retrospective analysis of 40 cases of distributive shock after heart surgery treated with vasopressin. These same authors included in their experience with this drug the heart transplant and patients who underwent mechanical circulatory assistance. In these patients, there was no hypertensive rebound, peripheral or mesenteric ischemia, closed to an improvement in blood pressure levels and decrease of the needs of catecholamines.

Based on this experience, Talbot et al. [30] published the case of a patient who had refractory hypotension at the beginning of the CPB, possibly associated with high levels of potassium cardioplegia and the prolonged use of diuretics and ramiprilat. It was used a unit of vasopressin bolus with immediate pressure response, suspension of catecholamines, and without any observable colateral effect. The efficiency and safety of this new and promising agent pressure needs further observation.

\section{Possible therapeutic strategies}

The corticosteroids have been used in heart surgery for more than 30 years. By its use is attributed to a number of effects: 1) improvement on hemodynamic conditions, 2) lower vasoconstriction with improved tissue perfusion, 3) cellular effects such as stabilization of the lysosome membrane, 4) inhibition of phospholipase A2 activation with stabilization of lipid cell membranes, 5) antiinflammatory activity with lower release of cytokines and inhibition of complement activation and, 6) Selective inhibition of iNOS demonstrated experimentally by the action of dexamethasone.

Although its use has an experimental and logical basis, many studies failed to demonstrate its real effectiveness. Some studies try to attribute an anti-inflammatory activity to the aprotinin in situations of ischemia-reperfusion and in association with the use of oxygenators with heparinized surface, but the controversial aspects about their concrete effectiveness does not justify its routine use.

Similarly, the use of antioxidants in the preoperative, the use of surface oxygenators with heparinized surface and depletion of leukocytes are also speculative subjects. But the use of techniques of ultrafiltration and "cell savers" may be considered important because these techniques are employed almost as a routine in American services, where there is the impression that the vasoplegic shock is not considered a serious problem as it is in our means. The removal of proinflammatory substances and the decrease of the contact of white blood cells with the CPB circuit certainly are useful functions of these two techniques [26]. These strategies are represented in Figure 4. 


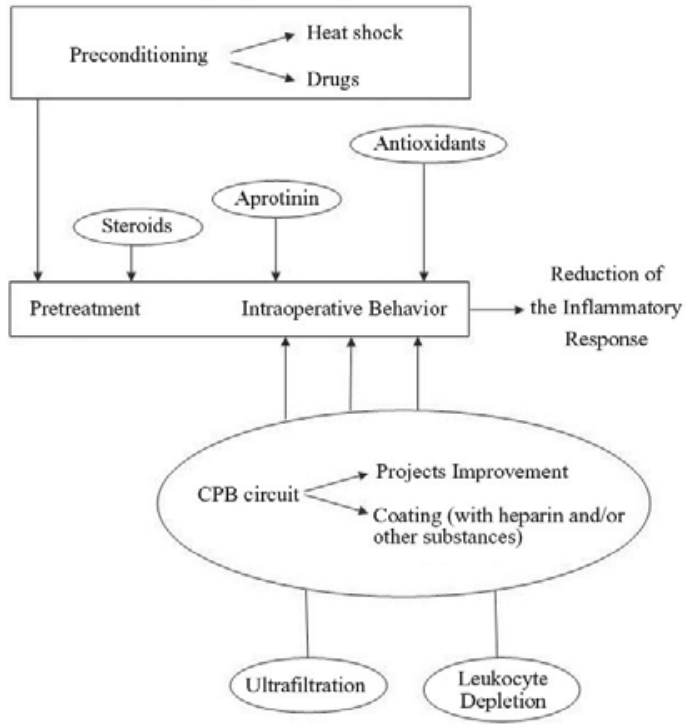

Fig. 4 - Possible therapeutic strategies to reduce the inflammatory response during cardiopulmonary bypass (Adapted from Wan et al. 1997)

The inhibition of guanylate cyclase by methylene blue as therapeutic propose for vasoplegia associated to cardiopulmonary bypass

The vasoplegic syndrome associated with the CPB was described by Gomes et al. [31] in 1994 and one of the authors of this update study proposed that the vasoplegia was dependent on the cyclic GMP system [32.33]. In clinical impossibility of specific inhibition of NO production from the L-arginine, it was proposed the inhibition of guanylate cyclase by the use of methylene blue, which, at present, seems to be the most reasonable proposal therapy since it does not interfere with the NO synthesis, and as a medication widely used in other clinical conditions. The action of methylene blue involves at inhibition of the guanylate cyclase avoiding the increase of cyclic GMP and thus avoiding the endothelium-dependent relaxation mediated by NO [34.35].

Although the methylene blue has been used for more than 13 years to treat vasoplegic syndrome, there are few quality clinical studies to adopt the protocol as treatment. Only three studies involving a larger number of patients deserve, due to their importance, the inclusion in this review about CPB [36]. In 2003, Leyh et al. [37] reported 54 cases of cardiac surgical patients with no bacterial endocarditis who were treated with methylene blue with response to the treatment of over $90 \%$ of patients. Levin et al. [38] reported the incidence of $8.8 \%$ of vasoplegic syndrome in 638 patients, with 56 patients randomized to receive vasoplegic methylene blue or placebo.
There were no deaths in the group that used methylene blue and the vasoconstrictor amines could be discontinued in a short time, with consequent lower morbidity and mortality. In the placebo group occurred two deaths, the use of amines lasted around 48 hours with the highest incidence of respiratory and kidney problems. This study supported the idea of methylene blue as efficient treatment of the vasoplegic syndrome.

Regarding to prevention of the vasoplegic syndrome, Ozal et al. [39], Turkey, in a prospective randomized study showed that methylene blue was associated with lower incidence of vasoplegia and less use of sympathetic amines. The criterion for inclusion of more patients in the study protocol was (in addition to the use of heparin) the use of ACE inhibitors. These two drugs are, up to now, the only ones considered as a risk factor for vasoplegic syndrome.

Finally, this study may not let to make considerations about the big "unanswered question" about the use of methylene blue: Why does the vasoplegic presentation reverse itself promptly sometimes, and occasionally seem not effective? Recently, a brilliant doctoral thesis was defended at the Federal University of Florianopolis (which has already been published by Fernandes et al. [40] ) and brings some very important data to attempt to answer that question.

Using a model of sepsis in mice, the authors demonstrated in a 24-hour period divided into three periods of eight hours, that there is a dynamic of action of guanylate cyclase so to create a "window of opportunity" for the efficiency of methylene blue to help restore the systemic vascular resistance. In the first eight hours, no longer occurs vasoreactivity not only by the action of amines, but also by the action of nitric oxide donor drugs.

This phase coincides with increased expression of iNOS. Between eight and sixteen hours, the expression of guanylate cyclase gradually cancels itself, probably by excessive production of nitric oxide, and thus in this stage the methylene blue may not act. Later, between sixteen and twenty-four hours, there would be "again" a synthesis of guanylate cyclase and the methylene blue may be effective again.

Considering these findings, we start to use the infusion of methylene blue even without an apparent effectiveness, waiting for the "window of opportunity", or that is, for the "again" synthesis of guanylate cyclase. One of our diabetic patients, who developed vasoplegic syndrome during the $\mathrm{CPB}$, presented an excellent response to methylene blue, but presented again serious vasoplegia in the surgical ICU without response to methylene blue. We maintained infusion of methylene blue in addition to high doses of adrenaline and noradrenaline. At the fourth postoperative day, we repeated new endovenous bolus of methylene blue 
and the response has been terrific and on the fifth day no longer was needed for infusion of amines to maintain arterial pressure and the stability of systemic vascular resistance in normal values.

\section{LUNG AND BRAIN PERFUSION IN CARDIOPULMONARYBYPASS}

The pulmonary infusion is temporarily interrupted during the CPB causing ischemia followed by reperfusion lesion. It is known that the blood supply of the lungs performs by means of two different systems: the pulmonary and bronchial circulation. The bronchial circulation irrigates the support tissue of the lungs with conjuntive tissue, septum and small bronchioles, while the pulmonary capillary circulation is made by the pulmonary artery branches. Connections between the pulmonary and bronchial circulations are particularly important in the absence of pulmonary circulation. In long-term, the bronchial circulation may extend and ensure the functions of affected areas [41].

Changes in pulmonary function after CPB is still very important because they are associated with increased morbidity and mortality. Two important mechanisms, the systemic inflammatory response and normothermic ischemic lesion have been implicated by these alterations. To avoid or prevent these alterations, the perfusion of pulmonary artery during the CPB with aortic clamping has been professed [42]. However, the perfusion of the pulmonary arteries during heart surgery with the use of CPB is not an usual and routine practice, even though the concept of ischemia lesion and pulmonary reperfusion is being showed (clinically and experimentally) as responsible for the deleterious effects in the postoperative period.

Some experimental studies have demonstrated that the perfusion maintenance of the pulmonary artery, with or without drugs, has the advantage of improving pulmonary function after CPB [42.43]. The advantages of the perfusion of the pulmonary trunk were recently demonstrated in a post-doctoral work developed in the Escola Paulista de Medicina - UNIFESP [44].

The possibility of maintenance of ventilation during the CPB improves the respiratory function of patients undergone heart surgery with CPB is controversial. Meanwhile, metanalysis performed with strategy based on evidence identified nine studies among 187, which when carefully examined showed no evidence favorable to the maintenance of ventilation during the $\mathrm{CPB}$.

That study showed a variety of strategies including ventilation: a) CPAP with positive pressure, $5-15 \mathrm{cmH}_{2} \mathrm{O}$ b) high-frequency ventilation (with $100 \mathrm{resp} / \mathrm{min}$ ), c) inspired fractions of oxygen from 21 to $100 \%$ and, d) bilateral CPB using the lungs to oxigenate the blood during the CPB. Althoug some small and transitional benefits have been observed with CPAP of $10 \mathrm{cmH} 2 \mathrm{O}$, no clinical benefit for any of ventilatory strategies during the CPB was established. Thus, ventilation during the CPB may not be considered as a strategy to improve the respiratory function of postoperative patients undergone heart surgery with CPB [45].

Unlike the pulmonary perfusion during the CPB, the selective brain perfusion has become consensus and may bring additional benefits to hypothermia during aortic surgery. In general, if it is accepted that the continuous perfusion brain promotes better protection brain, its association with hypothermia is still subject of controversy. One of them concerns the initial period of hypothermic cardiac arrest that may negatively affect the late evolution of surgical patients. Experimental evidence seem to demonstrate that the hypothermia does not involve these developments, perhaps by mechanisms of self-regulation of cerebral blood flow which rises along with their adaptation to the metabolic oxygenation [46].

Finally, it would be unfair if we not mention that the content of a class, showed on the Internet provided by Larson, was one of the motivating factors of this review [47].

\section{ESSENTIAL INFORMATIONS}

In conclusion of this critical review, follows some information that we consider essential throughout the text.

Surgeons must maintain and update their knowledge about CPB due the simple fact of maintaining its educational leadership over their team. On the other hand, it may be observed the impression that there is certain complacency in relation to the $\mathrm{CPB}$, since in recent times the quality of the material about $\mathrm{CPB}$ ensures large margin of safety for heart operations.

During $\mathrm{CPB}$, the circulation physiology is completely modified by the introduction of a nonpulsatile flow of arterial side opposed to high venous pressure on the venous side of circulation.

Together with the SvO2, which is valuable patient's metabolic rate during the $\mathrm{CPB}$, the $\triangle \mathrm{PCO} 2$ can help to fulfil the role in the adequacy of tissue perfusion during surgery. That gradient, perhaps one of the best parameters of tissue perfusion - possibly for lack of knowledge - is rarely used by our perfusionists.

The CPB techniques are clearly divided into protocols for children and protocols for adults. But, among adults, would not be interesting the elaboration of protocols individually? For example, the elderly and diabetics, due to their individual characteristics. Do they not deserve more appropriate protocols? 
Questioning about so decanted systemic inflammatory reaction caused by exposure of blood to the non-endothelial surface of CPB circuit. From verification that the inflammatory response is present in patients operated offpump, the focus changed to the concept that, rather than contact with the CPB circuit, the contact of blood with the operatory wound may be more responsible for phenomenon of inflammation in CPB.

Why does the vasoplegic presentation sometimes reverse itself promptly, and sometimes seem not be effective? Model of sepsis in mice, a "window of opportunity" for the efficiency of methylene blue to help to restore the systemic vascular resistance. This window of opportunity depends on the dynamics of action of guanylate cyclase, that by the intense release of NO by action of iNOS "saturates" itself, losing its activity for a few hours when their synthesis occur "again"; when the methylene blue becomes effective again. So, perhaps it worths to maintain the infusion of methylene blue, since the new synthesis of the enzyme occurs between 18 and 24 hours.

New technologies (impregnated circuits, "retrograde prime, minicircuits of $\mathrm{CPB}$, techniques to minimize the inflammatory reaction") have been "beneficial", "promising", without becoming unanimity in the face of routine and conventional techniques of CPB. Thus, as already mentioned, we must "persist on our daily faith that the body is incredibly able to resist and mostly often fixes this physiological chaos."

Alterations in pulmonary function after CPB is a very important subject because they are associated with increased morbidity and mortality. Two important mechanisms, the systemic inflammatory response and normothermic ischemic lesion have been implicated by these alterations. In order to avoid or prevent these alterations, the pulmonary artery perfusion during the CPB with aortic clamping - although not consensual - has been recommended.

Although some small and temporary benefits have been observed with CPAP of $10 \mathrm{cmH} 2 \mathrm{O}$, no clinical benefit for any of ventilatory strategies during the $\mathrm{CPB}$ was established. Thus, pulmonary ventilation during the CPB may not be considered as a strategy to improve the postoperative respiratory function of patients undergone on-pump heart surgery.

Unlike the pulmonary perfusion during the $\mathrm{CPB}$, the selective perfusion brain has become a consensus and may bring additional benefits to hypothermia during aortic surgery, but its association with hypothermia is still controversial. Experimental evidences seem to show that the initial hypothermia does not compromise this evolution, maybe by mechanisms of self-regulation of cerebral blood flow which rise along with their metabolic adaptation to the oxygenation. Experimental evidences seem to show that the initial hypothermia does not impair these developments, perhaps by mechanisms of self-regulation of cerebral blood flow, which rise along with its metabolic adaptation to oxygenation.

\section{REFERENCES}

1. De Souza MHL, Elias DO. Fundamentos da circulação extracorpórea. $2^{\mathrm{a}}$ ed. 2006. Disponível em: http://perfline.com/ livro/index.html

2. Évora PR. CEC: fisiologia e microcirculação. Aula ministrada no $34^{\circ}$ Congresso da Sociedade Brasileira de Cirurgia Cardiovascular, Florianópolis; 2007.

3. Barak M, Katz Y. Microbubbles: pathophysiology and clinical implications Chest. 2005;128(4):2918-32.

4. de Vroege R, te Meerman F, Eijsman L, Wildevuur WR, Wildevuur CHR, van Oeveren W, et al. Induction and detection of disturbed homeostasis in cardiopulmonary bypass. Perfusion. 2004;19(5):267-76.

5. Rousou JA, Engelman RM, Flack JE 3 $3^{\text {rd }}$, Deaton DW, Garb JL, Owen SG. The 'primeless pump': a novel technique for intraoperative blood conservation. Cardiovasc Surg. 1999;7(2):228-35.

6. Gibbon JH Jr. Application of a mechanical heart and lung apparatus to cardiac surgery. Minn Med. 1954;37(3):171-85.

7. Panico FG, Neptune WB. A mechanism to eliminate the donor blood prime from the pump-oxygenator. Surg Forum. 1960;10:605-9.

8. DeBois WJ, Rosengart TK. Retrograde autologous priming reduces blood use. Ann Thorac Surg. 1998;66(3):987-8.

9. Balachandran S, Cross MH, Karthikeyan S, Mulpur A, Hansbro SD, Hobson P. Retrograde autologous priming of the cardiopulmonary bypass circuit reduces blood transfusion after coronary artery surgery. Ann Thorac Surg. 2002;73(6):1912-8. 
10. Dunn J, Kirsh MM, Harness J, Carroll M, Straker J, Sloan H. Hemodynamic, metabolic, and hematologic effects of pulsatile cardiopulmonary bypass. J Thorac Cardiovasc Surg. 1974;68(1):138-47.

11. Reis CL, Evora PR, Ribeiro PJ, Brasil JC, Otaviano AG, Bongiovani HL, et al. Fluxo pulsátil em circulação extracorpórea. Apresentação de um sistema mecânico com estudos preliminares hemodinâmicos e do transporte de oxigênio. Arq Bras Cardiol. 1984;43(4):239-44.

12. Hindman B. Cerebral physiology during cardiopulmonary bypass: pulsatile versus nonpulsatile flow. Adv Pharmacol. 1994;31:607-16.

13. Perthel M, Kseibi S, Sagebiel F, Alken A, Laas J. Comparison of conventional extracorporeal circulation and minimal extracorporeal circulation with respect to microbubbles and microembolic signals. Perfusion. 2005;20(6):329-33.

14. Perthel M, El-Ayoubi L, Bendisch A, Laas J, Gerigk M. Clinical advantages of using mini-bypass systems in terms of blood product use, postoperative bleeding and air entrainment: an in vivo clinical perspective. Eur J Cardiothorac Surg. 2007;31(6):1070-5.

15. Mangoush O, Purkayastha S, Haj-Yahia S, Kinross J, Hayward M, Bartolozzi F, et al. Heparin-bonded circuits versus nonheparin-bonded circuits: an evaluation of their effect on clinical outcomes. Eur J Cardiothorac Surg. 2007;31(6):1058-69.

16. Campbell EJ, O’Byrne V, Stratford PW, Quirk I, Vick TA, Wiles MC, et al. Biocompatible surfaces using methacryloylphosphorylcholine laurylmethacrylate copolymer. ASAIO J. 1994;40(3):M853-7.

17. De Somer F, Francois K, van Oeveren W, Poelaert J, De Wolf D, Ebels T, et al. Phosphorylcholine coating of extracorporeal circuits provides natural protection against blood activation by the material surface. Eur J Cardiothorac Surg. 2000;18(5):602-6.

18. Deppisch R, Göhl H, Smeby L. Microdomain structure of polymeric surfaces - potential for improving blood treatment procedures. Nephrol Dial Transplant. 1998;13(6):1354-9.

19. Tonner PH, Kampen J, Scholz J. Pathophysiological changes in the elderly. Best Pract Res Clin Anaesthesiol. 2003;17(2):163-77.

20. Loran DB, Zwischenberger JB. Thoracic surgery in the elderly. J Am Coll Surg. 2004;199(5):773-84.

21. Matata BM, Galiñanes M. Cardiopulmonary bypass exacerbates oxidative stress but does not increase proinflammatory cytokine release in patients with diabetes compared with patients without diabetes: regulatory effects of exogenous nitric oxide. J Thorac Cardiovasc Surg. 2000;120(1):1-11.
22. Matata BM, Galiñanes M. Effect of diabetes on nitric oxide metabolism during cardiac surgery. Diabetes. 2001;50(11):2603-10.

23. Seghaye MC, Duchateau J, Grabitz RG, Wolff T, Marcus C, Engelhardt W, et al. Effect of sodium nitroprusside on complement activation induced by cardiopulmonary bypass: a clinical and experimental study. J Thorac Cardiovasc Surg. 1996;111(4):882-92.

24. Shanmugam G. Vasoplegic syndrome: the role of methylene blue. Eur J Cardiothorac Surg. 2005;28(5):705-10.

25. Pallas F, Larson DF. Cerebral blood flow in the diabetic patient. Perfusion. 1996;11(5):363-70.

26. Wan S, LeClerc JL, Vincent JL. Inflammatory response to cardiopulmonary bypass: mechanisms involved and possible therapeutic strategies. Chest. 1997;112(3):676-92.

27. Myles PS, Leong CK, Currey J. Endogenous nitric oxide and low systemic vascular resistance after cardiopulmonary bypass. J Cardiothorac Vasc Anesth. 1997;11(5):571-4.

28. Landry DW, Levin HR, Gallant EM, Seo S, D’Alessandro D, $\mathrm{Oz} \mathrm{MC}$, et al. Vasopressin pressor hypersensitivity in vasodilatory septic shock. Crit Care Med. 1997;25(8):1279-82.

29. Argenziano M, Choudhri AF, Oz Mc, Rose EA, Smith CR, Landry DW. A prospective randomised trial of arginine vasopressin in the treatment of vasodilatory shock after left ventricular assist device placement. Circulation. 1997;96(9 Suppl):II-286-90.

30. Talbot MP, Tremblay I, Denault AY, Bélisle S. Vasopressin for refractory hypotension during cardiopulmonary bypass. J Thorac Cardiovasc Surg. 2000;120(2):401-2.

31. Gomes WJ, Carvalho AC, Palma JH, Goncalves I Jr, Buffolo E. Vasoplegic syndrome: a new dilemma. J Thorac Cardiovasc Surg. 1994;107(3):942-3.

32. Andrade JCS, Batista Filho ML, Evora PRB, Tavares JR, Buffolo E, Ribeiro EE, et al. Methylene blue administration in the treatment of the vasoplegic syndrome after cardiac surgery. Rev Bras Cir Cardiovasc. 1996;11(2):107-14.

33. Évora PR. Should methylene blue be the drug of choice to treat vasoplegias caused by cardiopulmonary bypass and anaphylactic shock? J Thorac Cardiovasc Surg. 2000;119(3):632-4.

34. Évora PR, Levin RL. Methylene blue as drug of choice for catecholamine-refractory vasoplegia after cardiopulmonary bypass.J Thorac Cardiovasc Surg. 2004;127(3):895-6.

35. Évora PR, Viaro F. The guanylyl cyclase inhibition by MB as vasoplegic circulatory shock therapeutical target. Curr Drug Targets. 2006;7(9):1195-204. 
36. Leite EG, Ronald A, Rodrigues AJ, Évora PR. Is methylene blue of benefit in treating adult patients who develop catecholamine-resistant vasoplegic syndrome during cardiac surgery? Interact Cardiovasc Thorac Surg. 2006;5(6):774-8.

37. Leyh RG, Kofidis T, Strüber M, Fischer S, Knobloch K, Wachsmann B, et al. Methylene blue: the drug of choice for catecholamine-refractory vasoplegia after cardiopulmonary bypass? J Thorac Cardiovasc Surg. 2003;125(6):1426-31.

38. Levin RL, Degrange MA, Bruno GF, Del Mazo CD, Taborda DJ, Griotti JJ, et al. Methylene blue reduces mortality and morbidity in vasoplegic patients after cardiac surgery. Ann Thorac Surg. 2004;77(2):496-9.

39. Ozal E, Kuralay E, Yildirim V, Kilic S, Bolcal C, Kücükarslan $\mathrm{N}$, et al. Preoperative methylene blue administration in patients at high risk for vasoplegic syndrome during cardiac surgery. Ann Thorac Surg. 2005;79(5):1615-9.

40. Fernandes D, Silva-Santos JE, Duma D, Villela CG, BarjaFidalgo C, Assreuy J. Nitric oxide-dependent reduction in soluble guanylate cyclase functionality accounts for early lipopolysaccharide-induced changes in vascular reactivity. Mol Pharmacol. 2006;69(3):983-90.

41. Schlensak C, Doenst T, Preusser S, Wunderlich M, Kleinschmidt M, Beyersdorf F. Bronchial artery perfusion during cardiopulmonary bypass does not prevent ischemia of the lung in piglets: assessment of bronchial artery blood flow with fluorescent microspheres. Eur J Cardiothorac Surg. 2001;19(3):326-31.

42. Liu Y, Wang Q, Zhu X, Liu D, Pan S, Ruan Y, et al. Pulmonary artery perfusion with protective solution reduces lung injury after cardiopulmonary bypass. Ann Thorac Surg. 2000;69(5):1402-7.

43. Fan X, Liu Y, Wang Q, Yu C, Wei B, Ruan Y. Lung perfusion with clarithromycin ameliorates lung function after cardiopulmonary bypass. Ann Thorac Surg. 2006;81(3):896-901.

44. Gabriel EA. Perfusão do tronco pulmonar em cirurgias cardíacas com emprego de circulação extracorpórea [Tese PósDoutorado]. São Paulo:Universidade Federal de São Paulo, Escola Paulista de Medicina;2007.

45. Vohra HA, Levine A, Dunning J. Can ventilation while on cardiopulmonary bypass improve post-operative lung function for patients undergoing cardiac surgery? Interact Cardiovasc Thorac Surg. 2005;4(5):442-6.

46. Halstead JC, Etz C, Meier DM, Zhang N, Spielvogel D, Weisz $\mathrm{D}$, et al. Perfusing the cold brain: optimal neuroprotection for aortic surgery. Ann Thorac Surg. 2007;84(3):768-74.

47. Larson DF. Adequacy of perfusion during cardiopulmonary bypass: Empiric or scientific. Disponível em: www.kfshrc.edu.sa/perfusion/ education/Perfusion\%20Adequacy\%20FINAL\%202003. 